\title{
Carbonatação em concretos com agregados reciclados de concreto
}

\author{
Carbonation in concretes with recycled concrete \\ aggregates
}

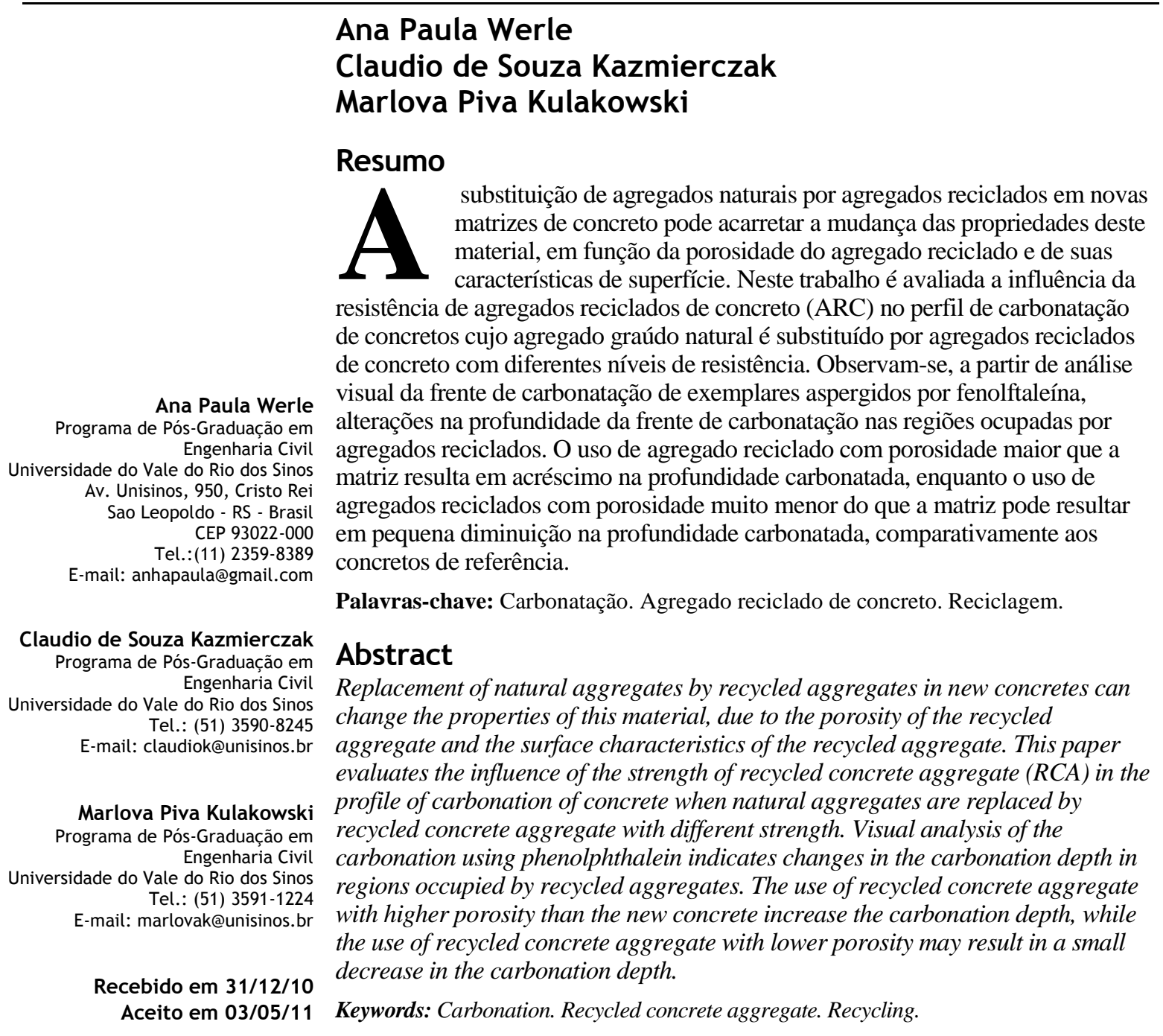

Ambiente Construído, Porto Alegre, v. 11, n. 2, p. 213-228, abr./jun. 2011. 


\section{Introdução}

A atividade de construção civil consome cerca de $20 \%$ a $75 \%$ de todos os recursos naturais. Ela é responsável pela geração de cerca de $50 \%$ de todo o resíduo sólido urbano produzido pela população (ÂNGULO et al., 2003).

Uma das alternativas para a reciclagem desse resíduo é sua transformação em agregados. $\mathrm{Na}$ forma deste coproduto, os resíduos podem retornar à cadeia produtiva da construção. A viabilidade técnica para a inserção desse material em novas matrizes cimentícias tem sido estudada por pesquisadores em todo o mundo (LEITE, 2001; KATZ, 2003; BUTLER, 2003; ETXEBERRIA et al., 2007; GOMES; BRITO, 2009; CORDINALDESI; MORICONI, 2009; PAPADAKIS; VAYENAS; FARDIS, 1991; CABRAL et al., 2010).

As contribuições originadas por esses estudos demonstram que é possível inserir resíduos de construção (RCD) em concretos para fins estruturais. Em alguns casos, substituindo parcialmente agregados naturais pelos agregados reciclados, observou-se um incremento no desempenho mecânico de concretos que contêm RCD (XIAO; LI; ZHANG, 2005).

As principais aplicações do RCD e do dos agregados recclados de concreto (ARC) ocorrem em bases e sub-bases de pavimentação (POON; CHAN, 2006; MELBOUCI, 2009). Os processos e custos de transporte, moagem e separação do agregado de concreto, entretanto, são fatores limitantes para a aplicação. Sob essa ótica, a utilização do ARC em aplicações mais nobres, como na fabricação de novos concretos, pode ser uma alternativa interessante. $O$ Guide for Specification of Recycled Concrete Aggregates (RCA) for Concrete Production - Final Report (CSIRO, 1998) indica que o agregado reciclado de concreto com massa específica superior a 2,1 $\mathrm{kg} / \mathrm{dm}^{3}$ e absorção de água inferior a $6 \%$ é adequado para reciclagem em novos concretos. A Environmental Protection Agency - EPA (2002), a partir de compilação de estudos realizados com base nos RCD/ARC, também indica que é possível se obterem concretos com propriedades mecânicas similares às de concretos sem resíduos. Entretanto, para o uso do ARC em funções estruturais, ainda há diversos problemas relacionados com a qualidade do agregado e do produto final que precisam ser resolvidos. Uma das questões ainda não esclarecidas é a durabilidade de novos concretos que incorporam ARC.

Para que agregados de ARC sejam plenamente incorporados, alguns aspectos devem ser levados em consideração, tais como a porosidade do agregado, a necessidade de empregar uma compensação de água em virtude da absorção do ARC e os teores de substituição do agregado natural pelo ARC. Alguns trabalhos apontam para um teor máximo de 50\% (GOMES; BRITO, 2009). Os aspectos citados interferem no comportamento do concreto tanto no estado fresco quanto no estado endurecido. Além da necessidade do material em atender aos requisitos de trabalhabilidade e solicitações mecânicas, deve constituir um componente durável.

Autores como Bazuco (1999), Ângulo (2000), Limbachiya, Leelawat e Dhir (2000), Leite (2001), Butler (2003), Gómez-Soberón (2003), Katz (2003), Lovato (2007), Cabral (2007), Padmini, Ramamurthy e Mathews (2009), Hui-Sheng, BiWan e Xiao-Chen (2009), entre outros, estudaram o comportamento do concreto com agregados de RCD mistos (compostos das frações cerâmica, concreto, argamassas) ou utilizando as frações que compõem o resíduo de maneira segregada. Esses estudos têm demonstrado que a inserção de agregados provenientes de RCD altera as propriedades do concreto. Entre as propriedades estudadas, a absorção de água por esse novo material é constantemente observada, e os resultados obtidos pelas pesquisas apontam que os concretos que incorporam resíduos tendem a ser mais porosos e, portanto, mais suscetíveis à ação dos agentes deletérios.

Cabral et al. (2010) tratam da durabilidade de concretos com RCD sob o prisma da absorção de água, cujos resultados apontam para um material mais poroso e menos durável. Gomes e Brito (2009) realizam uma abordagem mais abrangente, com o uso de agregado reciclado de concreto (ARC). Os autores submetem o material a ensaios de absorção de água, penetração de cloretos e carbonatação. Os resultados obtidos pelos pesquisadores apontam que os concretos feitos com até $50 \%$ de ARC apresentam comportamento semelhante ao concreto de referência.

Pode-se inferir a partir da revisão realizada que há, de fato, uma mudança de comportamento do concreto que incorpora RCD ou ARC. No entanto, o conhecimento das propriedades do ARC, identificando-se sua resistência, absorção de água e forma, em conjunto com a especificação de uma nova matriz e procedimento de mistura compatível com este agregado pode gerar um concreto com características similares às de um concreto confeccionado com agregados convencionais. 
O presente estudo tem por objetivo discutir a influência da porosidade do ARC sobre a frente de carbonatação. Para tanto, foram moldados corpos de prova de concreto com relação $\mathrm{a} / \mathrm{c}=0,64$, nos quais foram substituídos os agregados naturais (rocha basáltica) por diferentes níveis de ARC $(25 \%, 50 \%, 75 \%$ e $100 \%)$ provenientes de concretos com diferentes porosidades $(\mathrm{a} / \mathrm{c}=0,85$, $0,56$ e 0,43$)$ e efetuado procedimento de prémolhagem em diferentes percentuais $(0 \%, 25 \%$, $50 \%, 75 \%$ e $100 \%$ ) no ARC antes de sua incorporação à mistura.

\section{Carbonatação do concreto}

A hidratação do cimento gera, genericamente, silicatos de cálcio hidratado (C-S-H), que conferem resistência ao material, e hidróxido de cálcio $\left(\mathrm{Ca}(\mathrm{OH})_{2}\right)$, principal responsável pela geração de um ambiente alcalino $(\mathrm{pH}$ próximo de 13). No concreto armado, a elevada alcalinidade gera uma camada passivante ao longo das barras de aço, que as protegem do fenômeno da corrosão.

A carbonatação, que ocorre naturalmente em estruturas de concreto, é um fenômeno físicoquímico que resulta em mudanças na microestrutura e na diminuição do $\mathrm{pH}$ do concreto. Esse fenômeno pode despassivar o aço utilizado nas estruturas de concreto armado, permitindo a corrosão das armaduras, e por esse motivo são realizados diversos estudos sobre o tema (PAPADAKIS; VAYENAS; FARDIS, 1991; LEVY, 2001; KULAKOWSKI, 2002; KIRCHHEIM，2003; KATZ， 2003; MASCE; MIYAZATO; YODSUDJAI, 2003; PAULETTI, 2004, 2009; HUI-SHENG; BI-WAN; XIAOCHEN, 2009). O fenômeno da carbonatação pode ser ocasionado pelas reações químicas provenientes da interação entre os principais constituintes presentes na atmosfera, como o $\mathrm{CO}_{2}$ (gás carbônico) com os produtos da hidratação do cimento, que se encontram no líquido intersticial dos poros (CUNHA; HELENE, 2001). Segundo Bary e Sellier (2004), a reação ocorre, principalmente, com os íons cálcio, contidos na solução aquosa dos poros, em equilíbrio com os produtos de hidratação do cimento.

A reação básica de carbonatação consiste na combinação do $\mathrm{CO}_{2}$, que se encontra dissociado em meio aquoso, dentro dos poros do concreto, com o $\mathrm{Ca}(\mathrm{OH})_{2}$, que também está dissociado neste mesmo ambiente. Essa interação entre os elementos resulta na formação de $\mathrm{CaCO}_{3}$ (carbonato de cálcio) e $\mathrm{H}_{2} \mathrm{O}$ (água), de acordo com a reação expressa na equação 1 .

$\mathrm{Ca}(\mathrm{OH})_{2(\mathrm{~s})}+\mathrm{CO}_{2(\mathrm{~g})} \leftrightarrow \mathrm{CaCO}_{3(\mathrm{~s})}+\mathrm{H}_{2} \mathrm{O}_{(\mathrm{l})} \quad$ Eq. 1
A reação simplificada do fenômeno da carbonatação é utilizada pela maioria dos autores que abordam o tema (PAPADAKIS; VAYENAS; FARDIS, 1991; THIERY et al., 2007; PETER et al., 2008). Além do $\mathrm{Ca}(\mathrm{OH})_{2}$, há evidências de que as reações de carbonatação não ocorrem somente entre o $\mathrm{CO}_{2}$ e o $\mathrm{Ca}(\mathrm{OH})_{2}$, mas sim com todos os demais compostos hidratados do cimento, como o C-S-H (silicato de cálcio hidratado), sulfato trihidratado (etringita), monossulfato hidratado, $\mathrm{C}_{3} \mathrm{~S}$ (silicato tricálcico) e $\mathrm{C}_{2} \mathrm{~S}$ (silicato dicálcico) (PAPADAKIS; VAYENAS; FARDIS, 1991; PETER et al., 2008; WANG; LEE, 2009). Segundo Peter et al. (2008), outros álcalis presentes na pasta de cimento, em pequena quantidade, como $\mathrm{KOH}$ (hidróxido de potássio), $\mathrm{NaOH}$ (hidróxido de sódio) e $\mathrm{Mg}(\mathrm{OH})_{2}$ (hidróxido de magnésio), além das fases dos aluminatos, também estão suscetíveis à carbonatação.

A reação básica refere-se à combinação do $\mathrm{CO}_{2}$ com $\mathrm{Ca}(\mathrm{OH})_{2}$ em função da rapidez com que tais reações ocorrem em relação aos demais elementos carbonatáveis. $\mathrm{O} \mathrm{CO}_{2}$ reage com o $\mathrm{Ca}(\mathrm{OH})_{2}$ três vezes mais rápido do que reage com $\mathrm{C}-\mathrm{S}-\mathrm{H}$, vinte vezes mais rápido do que a reação com $\mathrm{C}_{2} \mathrm{~S}$ e cinquenta vezes mais rápido do que a reação com o $\mathrm{C}_{3} \mathrm{~S}$ (PETER et al., 2008), alterando substancialmente o $\mathrm{pH}$ do concreto. $\mathrm{O}$ consumo do $\mathrm{Ca}(\mathrm{OH})_{2}$ faz com que o $\mathrm{pH}$ do concreto diminua a níveis entre 9 e 8 , o que extingue a camada passivante do aço (ANDRADE, 1992). Conforme Bauer, Nepomuceno e Pozzan (2001), Bary e Sellier (2004), Puertas, Palacios e Vásquez (2006), Song e Kwon (2007), Meier et al. (2007), HuiSheng, Bi-Wan e Xiao-Chen (2009), Lo et al. (2009), entre outros, o fenômeno da carbonatação é um exemplo clássico de despassivação da armadura.Como resultado da corrosão da armadura, os produtos expansivos geram tensões internas, fissurando o concreto, facilitando $o$ entrada de agentes deletérios. Em estágios mais avançados do fenômeno, pode acarretar o colapso da estrutura.

\section{Fatores que exercem influência na carbonatação}

O fenômeno da carbonatação é diretamente dependente da concentração de $\mathrm{CO}_{2}$ no ambiente, do percentual de umidade do ar, da temperatura a que a estrutura está submetida e dos condicionantes intrínsecos do concreto, como o tipo de cimento, as adições, os agregados e a cura, que definem, segundo Castellote et al. (2009), a composição da mistura e sua estrutura de poros. 


\section{Concentração de $\mathrm{CO}_{2}$}

A difusão do $\mathrm{CO}_{2}$ na rede de poros se dá em função da diferença de concentração do gás entre os meios externo e interno (KAZMIERCZAK, 1995), e as diferenças entre as concentrações de $\mathrm{CO}_{2}$ interferem sensivelmente na difusão da carbonatação através da rede de poros do concreto. Segundo Helene (1993), a concentração de $\mathrm{CO}_{2}$ no meio externo varia de $0,03 \%$ a $0,05 \%$ para atmosferas rurais, de $0,1 \%$ a $1,2 \%$ para atmosferas urbanas onde há tráfego pesado de veículos, e em $1,8 \%$ em ambientes cuja atmosfera está viciada, onde não há troca de ar.

A escolha de determinado percentual de $\mathrm{CO}_{2}$ para a realização de ensaios acelerados de carbonatação não é consenso, havendo poucos trabalhos que contemplem diferentes concentrações de $\mathrm{CO}_{2}$ em um mesmo estudo (PAULETTI et al., 2009). Um dos principais objetos de discussão está na alteração do mecanismo da carbonatação e na microestrutura dos produtos resultantes, que deve ocorrer a partir de determinada concentração de $\mathrm{CO}_{2}$. Em geral, recomenda-se a adoção de baixos teores de $\mathrm{CO}_{2}$, inferiores a $10 \%$, sendo que estudos mais recentes indicam que a partir de uma concentração de $3 \%$ de $\mathrm{CO}_{2}$, pode haver alterações na microestrutura do material carbonatado (CASTELLOTE et al., 2009). A realização do ensaio acelerado de carbonatação utilizando-se uma concentração de $1 \%$ de $\mathrm{CO}_{2}$ garante que os produtos formados pelas reações de carbonatação são os mesmos gerados em condições naturais de exposição ao $\mathrm{CO}_{2}$, alterando a microestrutura do concreto da mesma forma que ocorre em exposição natural (PAULETTI, 2009).

\section{Umidade relativa}

Segundo Papadakis et al. (1991), o fenômeno da carbonatação não é perceptível em umidades relativas inferiores a 50\% (não há água suficiente para que as reações se processem). Por outro lado, quando os poros estão saturados, a velocidade de transporte do $\mathrm{CO}_{2}$, que ocorre por difusão, diminui excessivamente. Segundo Bary e Sellier (2004), as maiores velocidades de carbonatação ocorrem em umidades entre $40 \%$ a $80 \%$ (BARY; SELLIER, 2004), ou ainda entre $50 \%$ e $70 \%$, de acordo com Thiery et al. (2007). Em ensaios acelerados de carbonatação, a maioria dos estudos tem adotado a faixa de umidade relativa proposta por Thiery $e t$ al. (2007): 60 $\pm 5 \%$ (KATZ, 2003; LO et al., 2009); e 70 $\pm 5 \%$ (RYU, 2002; MASCE; MIYAZATO; YODSUDJAI, 2003; POSSAN, 2004; HUISHENG; BI-WAN; XIAO-CHEN, 2009).

\section{Temperatura}

$\mathrm{O}$ principal fator que rege a velocidade da carbonatação é a difusão do $\mathrm{CO}_{2}$, o qual é muito pouco afetado pela temperatura, segundo Papadakis, Vayenas e Fardis (1991). Helene (1993) observa que na evolução da carbonatação a influência da temperatura na velocidade de carbonatação foi pouco visível para temperaturas entre 25 e $30{ }^{\circ} \mathrm{C}$. Da mesma forma, Kulakowski (2002) aponta que para temperaturas entre 20 e 40 ${ }^{\circ} \mathrm{C}$ não há interferência significativa na velocidade de carbonatação.

\section{Cimento}

O tipo e a quantidade de cimento adotado para a confecção do concreto determinam a quantidade de compostos alcalinos disponíveis para reagir com o $\mathrm{CO}_{2}$, assim como as condições de cura, relação a/c e existência de fissuras, são determinantes para a velocidade em que ocorre o avanço da frente de carbonatação (FIGUEIREDO, 2005). A composição química do cimento é abordada por Kirchheim (2003) e Castellote et al. (2009), que relatam que a profundidade de carbonatação está condicionada à mesma.

\section{Adições}

As adições feitas às matrizes cimentícias exercem influência sobre o fenômeno da carbonatação, acelerando o fenômeno, quando alcalinas, ou retardando-o, quando propiciam o fechamento dos poros, dificultando a entrada de gás carbônico.

Pauletti (2004) observa que concretos confeccionados com cimentos que possuem adições tendem a carbonatar mais do que concretos confeccionados com cimentos comuns. Utilizando cimento pozolânico e cimento comum, confirmou que a profundidade de carbonatação é maior para argamassas confeccionadas com adição de pozolana em relação ao cimento comum. Venquiarutto, Isaía e Gastaldini (2002) encontram profundidades maiores de carbonatação em concretos com adições de maior finura. Quanto mais fina a adição, mais reativa, reagindo mais rapidamente com $\mathrm{Ca}(\mathrm{OH})_{2}$ e diminuindo a reserva alcalina do meio, sujeito à carbonatação. Bauer, Nepomuceno e Pozzan (2001) observam que em corpos de prova contendo sílica ativa, após passarem pela carbonatação, há uma alteração na distribuição de poros, que diminui o acesso de água aos poros do material. 


\section{Relação água/aglomerante}

A relação água/aglomerante influencia sensivelmente o avanço da frente de carbonatação, pois as características microestruturais do material são dependentes dessa relação. A interferência da relação $\mathrm{a} / \mathrm{c}$ e a/agl na profundidade de carbonatação é consensual e relatada por diversos autores (PAPADAKIS; VAYENAS; FARDIS, 1991; KULAKOWSKI, 2002; BAUER; NEPOMUCENO; POZZAN, 2001; HARTMANN et al., 2002; KIRCHHEIM, 2003; PAULETTI, 2004; TAM; GAO; TAM, 2005; DIESEL et al., 2006; MEIRA; PADARATZ; BORBA JÚNIOR, 2006; CASTELLOTE et al., 2009; WANG; LEE, 2009). Há tendência em se afirmar que, quanto maior a relação a/c e a quantidade de adições minerais, maior a velocidade de carbonatação.

\section{Cura}

A condição de cura dos corpos de prova é um fator relevante para o desempenho das estruturas de matriz cimentícia. Quanto melhores as condições de cura, melhores serão as propriedades do concreto, pois ela melhora as condições de hidratação, processo que tende a diminuir a porosidade do concreto (HELENE, 1993). Pauletti (2009) infere que, aumentando o tempo de cura, há diminuição da profundidade de carbonatação, em função do grau de hidratação obtido e minimização das retrações decorrentes da secagem.

\section{Tipo de agregado}

Entre os fatores que influenciam o comportamento da carbonatação no concreto, o tipo de agregado utilizado na mistura do concreto é tratado como um fator com menor importância para o fenômeno, pois os agregados são considerados inertes em relação à carbonatação. Ao comparar a carbonatação entre concretos e argamassas, Papadakis, Vayenas e Fadis (1991) ressaltam que a presença do agregado não afeta sensivelmente a difusão do $\mathrm{CO}_{2}$, pois a presença da interface pasta/agregado parece compensar a "falta" de porosidade do agregado natural.

No entanto, quando confeccionados concretos que incorporam agregados reciclados de concreto (ARC), observa-se consenso entre os pesquisadores em relação à alteração da porosidade do concreto. As consequências do uso desses materiais são discutidas a seguir.

\section{Carbonatação em concretos com RCD e ARC}

Diversos pesquisadores afirmam que a substituição de agregados naturais por agregados reciclados resulta em um concreto com maior porosidade que o concreto de referência (BAZUCO, 1999; LEVY, 2001; LEITE, 2001; BUTLER, 2003; CABRAL, 2007). Desse modo, como consequência da maior porosidade, pode-se estimar que a velocidade de carbonatação nos concretos com agregado reciclado seja maior. Tal afirmação, entretanto, ainda não é consenso.

Cabral (2007) determinou as propriedades mecânicas e a durabilidade de concretos produzidos com agregados reciclados, verificando que, independentemente do tipo de agregado reciclado inserido em uma nova matriz de concreto, esse concreto aumentará o volume de poros total. $O$ autor também afirma que a velocidade de carbonatação é determinada pela relação a/agl da nova pasta. Em contraposição a Cabral (2007), Levy (2001) constatou que, para agregados provenientes de concretos de 20 e 30 $\mathrm{MPa}$, inseridos em uma nova matriz de $40 \mathrm{MPa}$, a profundidade de carbonatação é menor que a do concreto de referência (de $40 \mathrm{MPa}$ ), sugerindo a formação de uma barreira, localizada na interface pasta/ARC, que minimiza a carbonatação. Esse fenômeno deve ocorrer, segundo ele, em função da existência de microfissuras e da existência de material cimentante anidro no agregado reciclado. O mesmo autor, entretanto, afirma que, em teores de substituição superiores a $20 \%$, poderá haver perda de durabilidade.

Segundo estudos de Cordinaldesi e Moriconi (2009), quanto menor a relação a/c, menor a profundidade de carbonatação, independentemente da quantidade de ARC inserido no concreto, devido a uma reorganização dos poros da pasta. Os autores apontam para o fato de os agregados reciclados possuírem compostos alcalinos, que, somados à alcalinidade da pasta nova, protegem o concreto contra a carbonatação, podendo preservar a integridade da armadura por mais tempo do que um concreto convencional.

De acordo com Gomes e Brito (2009), em concretos com adição de agregados reciclados, não há aumento expressivo na profundidade de carbonatação em relação a um concreto convencional. Porém, uma substituição acima de $50 \%$ de agregado natural por reciclado resulta em acréscimos na ordem de $10 \%$ na profundidade de carbonatação. A afirmação feita por esses autores pode ser considerada como uma tendência, porém o máximo teor de substituição de agregados naturais por agregados reciclados sem alteração significativa da durabilidade será função das especificidades do novo concreto e das características do resíduo utilizado. 
Em vista do exposto, fica claro que não há consenso sobre o fenômeno e que, antes de se substituírem agregados naturais por agregados reciclados, faz-se necessária a realização de análises que permitam estimar o comportamento do novo concreto ante a ação do $\mathrm{CO}_{2}$.

\section{Programa experimental}

Neste trabalho realiza-se uma comparação da carbonatação entre concretos com agregados convencionais e concretos em que é utilizado agregado reciclado de concreto obtido a partir da cominuição, em britador de mandíbulas, de concretos com diferentes resistências $(18,37$ e 50 $\mathrm{MPa})$.

\section{Materiais utilizados}

O cimento utilizado foi o cimento Portland de alta resistência inicial - CP V ARI, curado durante 63 dias, de modo a permitir um grau de hidratação elevado.

O agregado miúdo empregado é uma areia de origem quartzoza, com distribuição granulométrica visualizada na Tabela 1.

O agregado graúdo natural adotado para a pesquisa é de origem basáltica, apresenta módulo de finura de 6,69, dimensão máxima de $19 \mathrm{~mm}$, massa específica igual a $2,75 \mathrm{~g} / \mathrm{cm}^{3}$, massa unitária igual a $1,49 \mathrm{~g} / \mathrm{cm}^{3}$ e distribuição granulométrica de acordo com a Tabela 2. Esse material passou por processo de lavagem (para remoção de finos aderidos aos agregados) e secagem, antes de sua utilização.

\section{Dosagem e caracterização dos concretos de origem dos agregados reciclados}

Com o intuito de conhecer as propriedades e características dos agregados de concreto utilizados na pesquisa, estes foram fabricados em laboratório. O concreto foi dosado segundo o método proposto por Helene e Terzian (1993), adotando-se um teor de argamassa $\alpha=49 \%$ e fixando-se o abatimento em $100 \pm 20 \mathrm{~mm}$. Foram adotadas as resistências de dosagem de 18, 37 e 50 $\mathrm{MPa}$ (obtidas segundo o procedimento recomendado pela NBR NM 101 (ABNT, 1997)). Os concretos foram moldados na forma de corpos de prova cilíndricos, com diâmetro de $10 \mathrm{~cm}$ x 20 $\mathrm{cm}$ de altura, e submetidos a cura submersa por 63 dias, na temperatura de $21^{\circ} \mathrm{C}$. As resistências a tração por compressão diametral, determinadas segundo especificado pela ABNT NBR NM 8 (ABNT, 1995), foram de 7, 11 e $14 \mathrm{MPa}$ respectivamente.

Os agregados graúdos reciclados foram obtidos a partir da cominuição desses concretos, em britador de mandíbulas. $\mathrm{O}$ processo posterior de peneiramento foi realizado para a separação da fração passante pela peneira de abertura \# $25 \mathrm{~mm}$ e retida na peneira de abertura \# 4,8 $\mathrm{mm}$, em função da dimensão máxima característica do agregado de referência.

Os agregados obtidos possuem uma distribuição granulométrica próxima da zona delimitada entre as peneiras $12,5 \mathrm{~mm}$ e $25 \mathrm{~mm}$, conforme visualizado na Figura 1. A caracterização física dos agregados consta na Tabela 3. A diferença de porosidade entre os agregados reciclados pode ser exemplificada pela capacidade de absorção de água, apresentada na Tabela 3, bem como por meio das curvas apresentadas no gráfico de porosidade, obtidas através de porosimetria por intrusão de mercúrio (Figura 2). A análise dessas caracterizações indica que a porosidade total acumulada diminui à medida que se aumenta a resistência do concreto de origem do agregado reciclado.

Tabela 1 - Distribuição granulométrica do agregado miúdo natural - NBR NM248 (ABNT, 2001)

\begin{tabular}{ccc}
\hline Abertura de peneira & Média retida & Média acumulada \\
\hline$\# 4,8 \mathrm{~mm}$ & 3 & 3 \\
$\# 2,4 \mathrm{~mm}$ & 11 & 14 \\
$\# 1,2 \mathrm{~mm}$ & 18 & 32 \\
$\# 0,6 \mathrm{~mm}$ & 18 & 50 \\
$\# 0,3 \mathrm{~mm}$ & 27 & 77 \\
$\# 0,15 \mathrm{~mm}$ & 20 & 97 \\
$\# 0,075 \mathrm{~mm}$ & 3 & 100 \\
$<0,15 \mathrm{~mm}$ & 0 & 100 \\
\hline
\end{tabular}

218 Werle, A. P.; Kazmierczak, C. de S.; Kulakowski, M. P. 
Tabela 2 - Distribuição granulométrica do agregado graúdo natural - NBR NM248

\begin{tabular}{ccc}
\hline Abertura de peneira & Média retida & Média acumulada \\
\hline$\# 25 \mathrm{~mm}$ & 0 & 0 \\
$\# 19 \mathrm{~mm}$ & 2 & 2 \\
$\# 12,5 \mathrm{~mm}$ & 60 & 62 \\
$\# 9,5 \mathrm{~mm}$ & 32 & 94 \\
$\# 6,3 \mathrm{~mm}$ & 6 & 100 \\
$\# 4,8 \mathrm{~mm}$ & 0 & 100 \\
$<4,8 \mathrm{~mm}$ & 0 & 100 \\
\hline
\end{tabular}

Fonte: ABNT (2001).

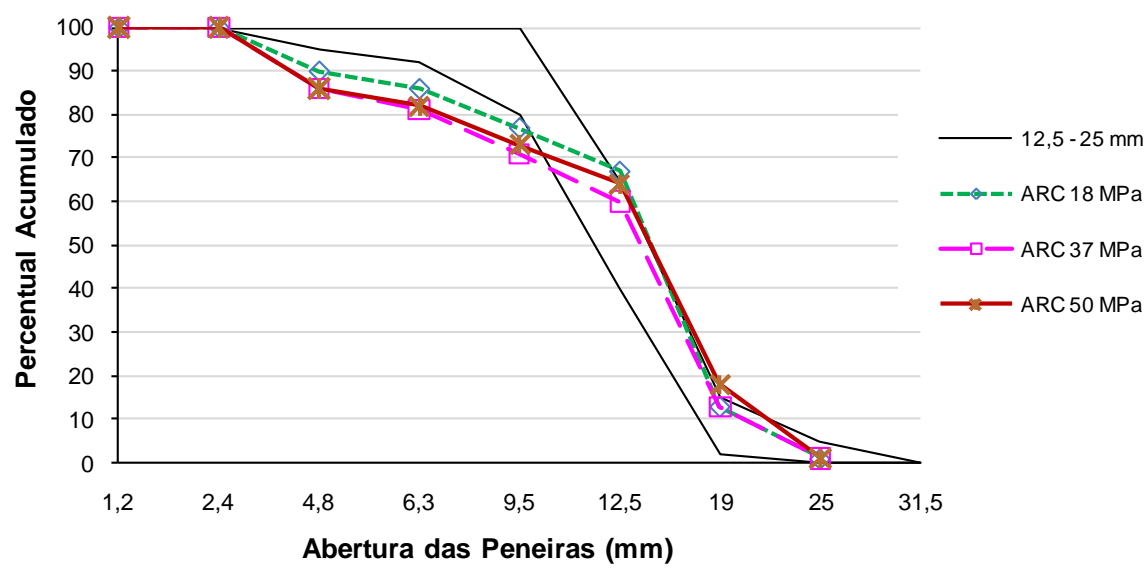

Figura 1 - Curva granulométrica dos agregados graúdos reciclados de concreto

Tabela 3 - Caracterização física dos agregados graúdos reciclados de concreto

\begin{tabular}{cccccc}
\hline $\begin{array}{c}\text { Resistência do } \\
\text { concreto de } \\
\text { origem ARC } \\
(\mathbf{M P a})^{*}\end{array}$ & $\begin{array}{c}\text { Dimensão } \\
\text { máxima } \\
(\mathbf{m m})\end{array}$ & $\begin{array}{c}\text { Módulo } \\
\mathbf{d e} \\
\text { finura }\end{array}$ & $\begin{array}{c}\text { Massa específica } \\
\left(\mathbf{g} / \mathbf{c m}^{2}\right)-\mathbf{N M} \text { 52/2009 } \\
-\mathbf{N M ~ 5 3 / 2 0 0 9}\end{array}$ & $\begin{array}{c}\text { Massa unitária } \\
\left(\mathbf{g} / \mathbf{c m}^{2}\right)-\mathbf{N M} \\
\mathbf{4 5 / 2 0 0 6}\end{array}$ & $\begin{array}{c}\text { Absorção } \\
(\mathbf{\%})\end{array}$ \\
\hline 18 & 25 & 7,68 & 2,50 & 1,21 & 8,49 \\
37 & 25 & 7,61 & 2,47 & 1,20 & 6,07 \\
50 & 25 & 7,70 & 2,49 & 1,21 & 5,24 \\
\hline
\end{tabular}

Nota: *A resistência do concreto de origem foi adotada como identificação dos tipos de ARC produzidos.

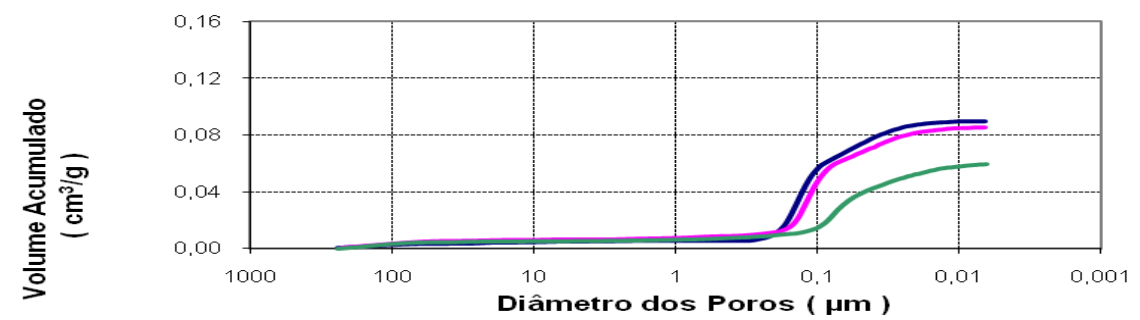

Figura 2 - Volume acumulado de poros dos agregados reciclados de concreto

\section{Execução dos corpos de prova e realização dos ensaios de carbonatação}

Nessa nova matriz de concreto empregaram-se substituições de agregado natural por ARC nos níveis de 25\%, 50\%, $75 \%$ e 100\%. As substituições foram realizadas considerando-se a compensação de volume do ARC através da massa específica do ARC e agregado natural de acordo com a equação 2 .

$$
M_{A R C}=\frac{M_{A N}}{\mu_{A N}} \times \mu_{A R C}
$$


Onde:

$\mathrm{M}_{\mathrm{ARC}}=$ massa do agregado reciclado;

$\mathrm{M}_{\mathrm{AN}}=$ massa do agregado natural;

$\gamma_{\mathrm{AN}}=$ massa específica do agregado natural; $\mathrm{e}$

$\gamma_{\mathrm{ARC}}=$ massa específica do agregado reciclado.

A etapa de pré-molhagem nos níveis de 0, 25, 50, 75 e $100 \%$, foi realizada em relação à capacidade de absorção do agregado. Esse procedimento foi realizado em sala com umidade controlada a $85 \pm$ $5 \%$ de UR, de modo que a água destinada à molhagem dos agregados não fosse perdida para o meio.

Os teores de agregados submetidos à prémolhagem foram empregados em uma matriz com traço de $1: 3,13: 3,67$ (cimento : agregado miúdo : agregado graúdo) com uma relação a/c de 0,64 (correspondente à utilizada na dosagem dos agregados com resistência de $37 \mathrm{MPa}$ ). Essa relação a/c foi estipulada a partir da necessidade de execução de ensaio acelerado de carbonatação em um período restrito (147 dias). Em função desse fator, o uso de uma relação a/c menor poderia acarretar na impossibilidade de observação de profundidade carbonatada nesse intervalo de tempo. Foi necessário ajustar o teor de argamassa para $\alpha=53 \%$, de modo a garantir a trabalhabilidade da pasta em função da inserção do ARC.

Além do ajuste do teor de argamassa, realizou-se um ajuste no conteúdo de água de cada concreto. Fixou-se um abatimento de $100 \pm 20 \mathrm{~mm} \mathrm{e}$, para alcançar esse fator predeterminado, cada combinação realizada possui uma relação $\mathrm{a} / \mathrm{c}$ distinta. Dessa forma, o programa experimental possui uma variável independente.

Os concretos foram moldados em formas prismáticas $(60 \mathrm{~mm} \quad$ x $60 \mathrm{~mm} \quad$ x $180 \mathrm{~mm})$, adensados em mesa vibratória, sendo desmoldados após 24 h e mantidos em cura submersa em tanques com solução saturada de água e cal por um período de 63 dias. Após, as amostras foram submetidas a um processo de sazonamento para adequarem-se à umidade interna especificada para o ensaio de carbonatação (aproximadamente 70\%). Para a realização desse procedimento utilizou-se a recomendação RILEM TC 116PCD (1999) (alterando-se a forma de moagem do corpo de prova) para determinar a massa aparente das amostras com a umidade requerida. Assim que as amostras atingem a massa aparente estipulada (em estufa ventilada a $50^{\circ} \mathrm{C}$ ), são seladas em embalagens impermeáveis, onde permanecem por 28 dias, para possibilitar o equilíbrio interno de umidade do corpo de prova. Após o período de reequilíbrio da umidade interna, os corpos de prova foram seguiram para o ensaio acelerado de carbonatação. A câmara utilizada para a carbonatação foi ajustada para uma concentração de $1 \%$ de $\mathrm{CO}_{2}$ e umidade relativa de $70 \% \pm 5 \%$. O tempo total de ensaio foi de 147 dias, após o qual se determinou a frente de carbonatação dos exemplares, a partir da ruptura do corpo de prova e aspersão do indicador químico fenolftaleína.

A medição das profundidades de carbonatação foi realizada por meio de análise de imagem. Após a aspersão de fenolftaleína, as amostras foram fotografadas e importadas para análise no software AutoCad. Através da ferramenta polilinha, determinou-se o contorno de toda a área de interesse e, em seguida, foram traçadas linhas paralelas, equidistantes entre si, somando 18 linhas para cada face analisada, de acordo com a ilustração das Figuras 3 e 4. Desta forma, foram feitas 36 medidas de profundidade de carbonatação para um mesmo corpo de prova. Esse procedimento foi realizado para 2 exemplares de cada combinação, gerando 72 medições, proporcionando uma profundidade média confiável.

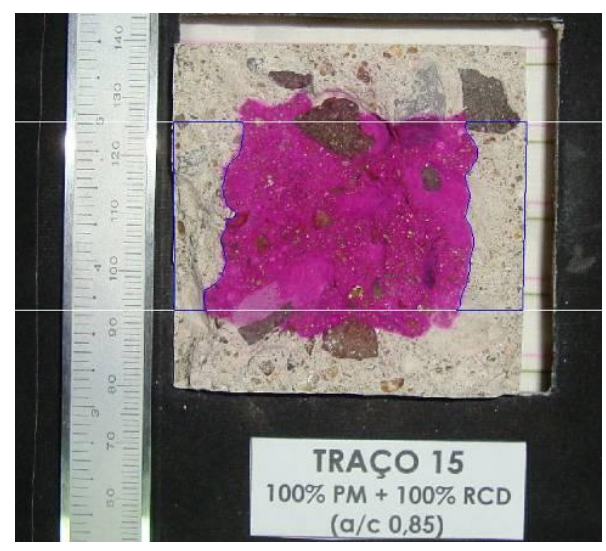

Figura 3 - Seleção de áreas de interesse 


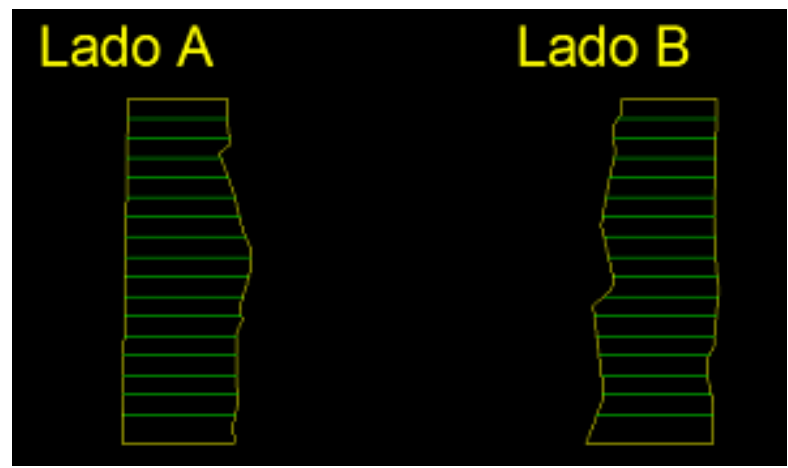

Figura 4 - Pontos de profundidade de carbonatação

Partindo da hipótese de que os agregados reciclados se comportam de forma distinta à dos agregados naturais, gerando uma frente de carbonatação não uniforme, e considerando a aparente impossibilidade de se distinguirem os ARC dos agregados naturais nos corpos de prova aspergidos por fenolftaleína, foi elaborada uma metodologia para a identificação dos agregados reciclados. Esta consiste na aspersão de fenolftaleína em exemplares recém-fraturados e na identificação da frente de carbonatação; manutenção dos mesmos em sala com umidade e temperatura controladas (UR $=70 \pm 5 \%$ e $\mathrm{T}=21 \pm$ $2{ }^{\circ} \mathrm{C}$ ) em contato com o $\mathrm{CO}_{2}$ presente nessa atmosfera por 7 dias; e na reavaliação da frente de carbonatação indicada pela fenolftaleína. Partiu-se da hipótese de que, em função da diferença de porosidade entre os agregados de ARC e a pasta do concreto novo, a velocidade de carbonatação na face fraturada dos exemplares que foram submetidos a carbonatação seria diferente e passível de ser identificada pela perda de coloração da fenolftaleína. Desse modo, torna-se possível identificar se há influência da porosidade do ARC sobre a frente de carbonatação.

\section{Análise e discussão dos resultados}

A Figura 5 apresenta os resultados médios de profundidade de carbonatação, obtidos para cada classe de resistência de agregado utilizado.

Observa-se que há uma tendência ao aumento da profundidade de carbonatação à medida que a resistência do agregado utilizado diminui. A partir de análise estatística dos resultados, detalhada na dissertação de mestrado de Werle (2010), pode-se verificar que não há variação significativa na profundidade de carbonatação entre os concretos de referência e concretos com agregados provenientes das matrizes de 50 e $37 \mathrm{MPa}$ (com resistência similar ou superior à do novo concreto - 32,5 MPa). Entretanto, ao se utilizar um agregado proveniente de concreto com resistência inferior (ARC de $18 \mathrm{MPa}$ ) à da nova matriz, a diferença na profundidade de carbonatação tornase significativa.

Outro aspecto relevante observado nos resultados é o aumento na dispersão dos mesmos, que ocorre ao se inserir o agregado reciclado à matriz, e que se torna expressivo ao se utilizar o ARC de maior porosidade (ARC de $18 \mathrm{MPa}$ ).

As imagens realizadas uma semana após aspersão, permitem realizar uma análise qualitativa a respeito da velocidade de carbonatação. É importante salientar que essa análise não contempla um estudo estatístico do fenômeno observado, no entanto tal comportamento foi observado para os demais corpos de prova verificados.

A Figura 6 apresenta o registro fotográfico da amostra do concreto de referência no momento da fratura e após 7 dias de contato com o ambiente.

Pode-se notar uma perda homogênea de coloração do indicador químico fenolftaleína durante o período em que a amostra estava exposta às condições do ambiente.

Na Figura 7 é possível visualizar concretos confeccionados com ARC, mais poroso que a matriz (com relação $\mathrm{a} / \mathrm{c}=0,85$ ). A presença dos ARC em algumas regiões do novo concreto é determinante para a forma como ocorre a penetração do $\mathrm{CO}_{2}$, sendo possível verificar, nos detalhes A e B, a presença de um ARC mais poroso que a matriz, que permitiu a entrada de $\mathrm{CO}_{2}$ com maior velocidade em relação ao observado na argamassa do concreto novo. 


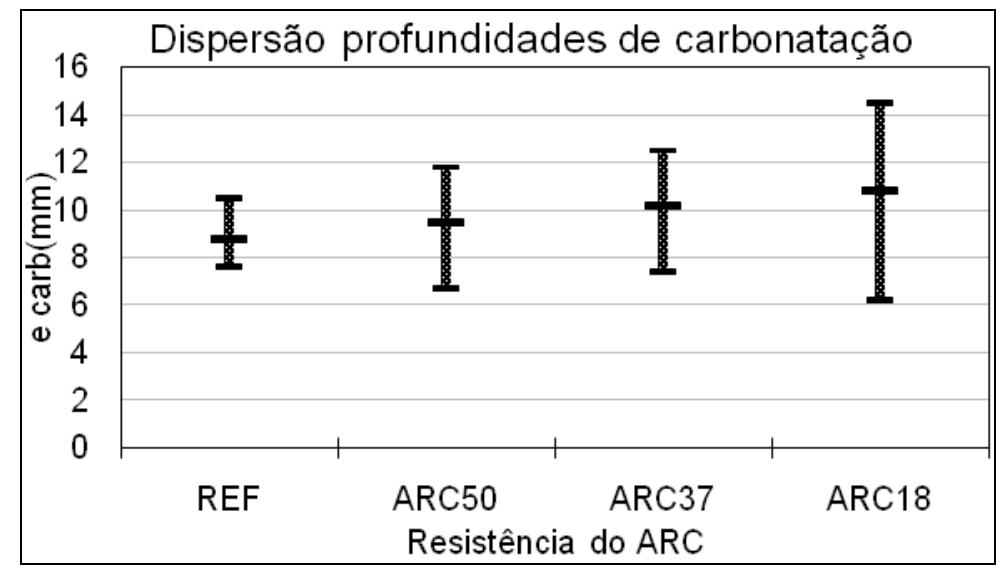

Figura 5 - Resultados médios de profundidade de carbonatação

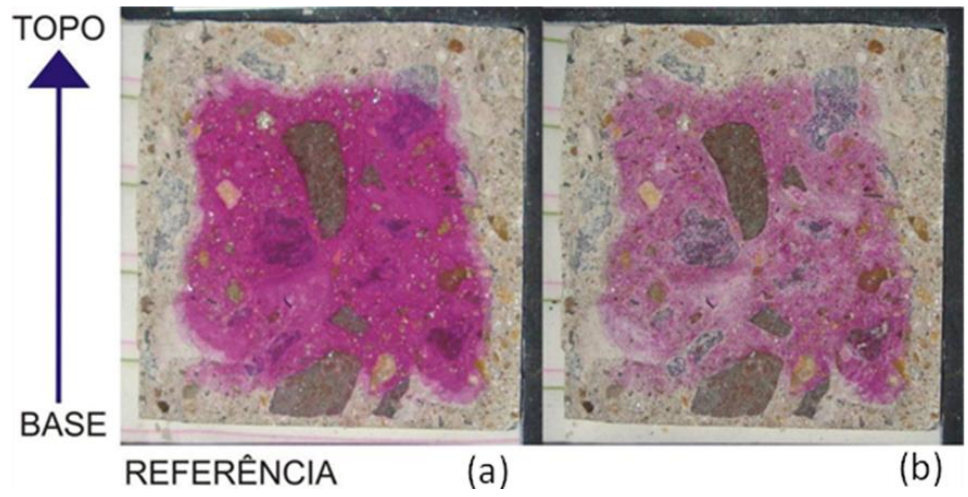

Figura 6 - (a) Frente de carbonatação imediatamente após a aspersão de fenolftaleína e (b) após 7 dias da aspersão, na amostra de referência

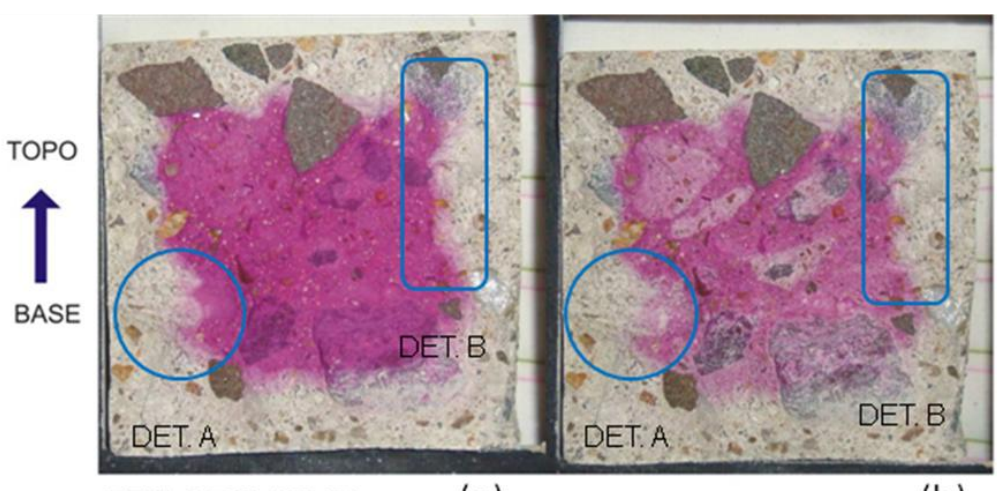

$75 \%$ ARC 18MPa

(a)

(b)

Figura 7 - (a) Frente de carbonatação imediatamente após a aspersão de fenolftaleína e (b) após 7 dias da aspersão, em exemplar com $75 \%$ de ARC a $18 \mathrm{MPa}$ 


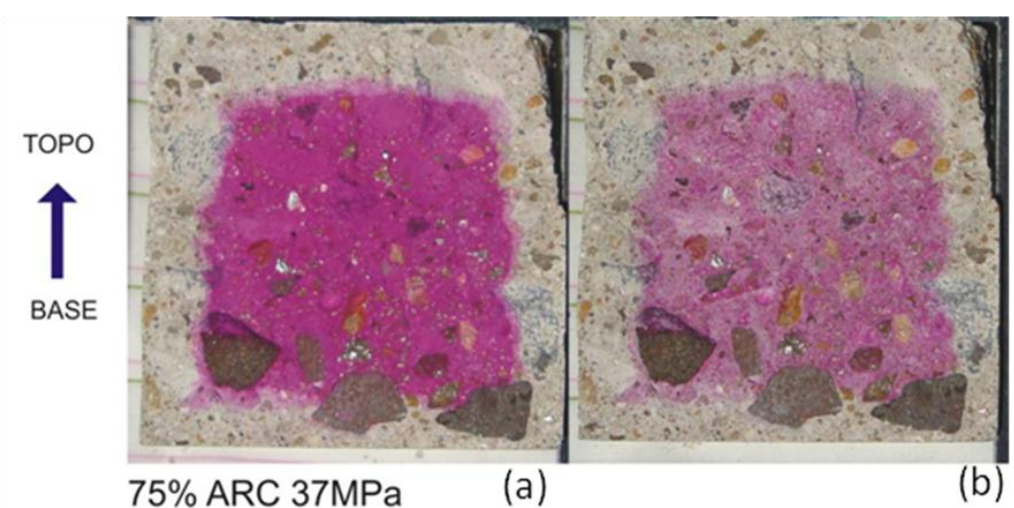

Figura 8 - (a) Frente de carbonatação imediatamente após a aspersão de fenolftaleína e (b) após 7 dias da aspersão, em exemplar com $75 \%$ de ARC a $37 \mathrm{MPa}$

$\mathrm{Na}$ Figura 8 pode-se visualizar um concreto confeccionado com ARC com relação a/c de 0,56. Nota-se que há uma descoloração uniforme do indicador químico fenolftaleína durante o período de 7 dias. Esse comportamento pode ser atribuído ao fato de que o ARC empregado possui uma relação a/c próxima da relação $\mathrm{a} / \mathrm{c}$ da pasta de concreto da nova matriz $(0,64)$, verificando-se que o comportamento do concreto que insere ARC de qualidade semelhante proporciona um comportamento homogêneo.

A última situação (Figura 9) refere-se ao concreto em que foi inserido um ARC com qualidade superior à da nova matriz (ARC com relação $\mathrm{a} / \mathrm{c}=$ 0,43). Pode-se notar que este ARC apresenta um comportamento similar ao agregado natural, impedindo o acesso do $\mathrm{CO}_{2}$ para o interior do concreto, visualizado nos detalhes $\mathrm{C}, \mathrm{D}$ e E.

As imagens analisadas demonstram que existem diferenças na velocidade de carbonatação de acordo com a porosidade do ARC inserido no concreto. É possível inferir que, quando empregado um ARC de maior porosidade, há uma tendência de aumento na velocidade de carbonatação. A presença das partículas mais porosas facilita a passagem do $\mathrm{CO}_{2}$ para o interior do concreto. Por outro lado, quando inseridos agregados com porosidade igual ou inferior à da matriz, não há influência sensível em relação ao comportamento do concreto de referência quanto à carbonatação.

As tendências observadas através das imagens são confirmadas através das medidas de profundidade de carbonatação. A análise estatística dos dados, realizada por meio de regressão múltipla não linear, retornou o modelo de comportamento da Equação 3, em que se pode observar como as variáveis estudadas influenciam na carbonatação. O modelo ajustado indicou um coeficiente de determinação $\mathrm{r}^{2}$ de 0 , 97, ou seja, o modelo proposto explica $97 \%$ dos dados verificados para o fenômeno da carbonatação, sendo os fatores (variáveis e interações) contemplados no modelo, significativos para um intervalo de confiança de $95 \%$ ( $\alpha 5 \%)$, pois o valor ' $p$ ' desses fatores foi menor que 0,05 (WERLE, 2010).

$\mathrm{EC}=\mathrm{EXP}(1,28513+(18,8571 / \mathrm{FC})+(0,172024 / \mathrm{ACF})$ $\left.+\left(11,6286^{*} \mathrm{TAG} / \mathrm{FC}\right)+\left(0,77336^{*} \mathrm{ACF} / \mathrm{TAG}\right)\right)^{*}\left(\mathrm{~T}^{\wedge} 1\right.$ ,20895)

Eq. 3

Onde:

$\mathrm{EC}=$ profundidade de carbonatada $(\mathrm{mm}) ;$

$\mathrm{FC}=$ resistência do concreto de origem do agregado (MPa);

$\mathrm{ACF}=$ relação água/cimento final;

TAG = teor de substituição de agregado (valores entre $25 \%$ e $100 \%$ ); e

$\mathrm{T}=$ tempo de exposição $(\sqrt{ }(\operatorname{dias}))$.

A Figura 10 apresenta os resultados de carbonatação para a idade de 147 dias, onde pode ser visualizada a diferença existente na profundidade de carbonatação para os concretos compostos com os diferentes tipos de ARC, comparado-se as curvas de comportamento (valores calculados) com os dados experimentais (valores observados). 


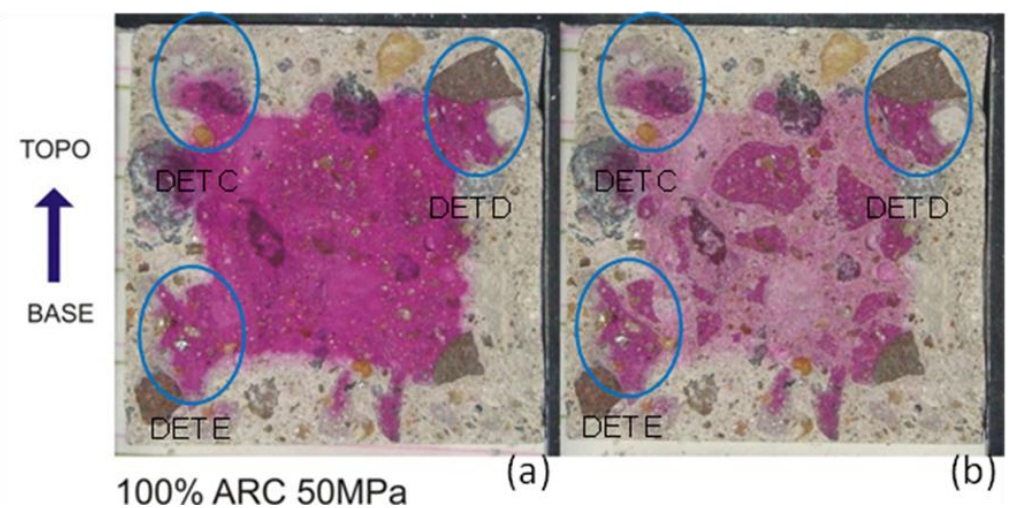

Figura 9 - (a) Frente de carbonatação imediatamente após a aspersão de fenolftaleína e (b) após 7 dias da aspersão, em exemplar com $75 \%$ de ARC a $50 \mathrm{MPa}$

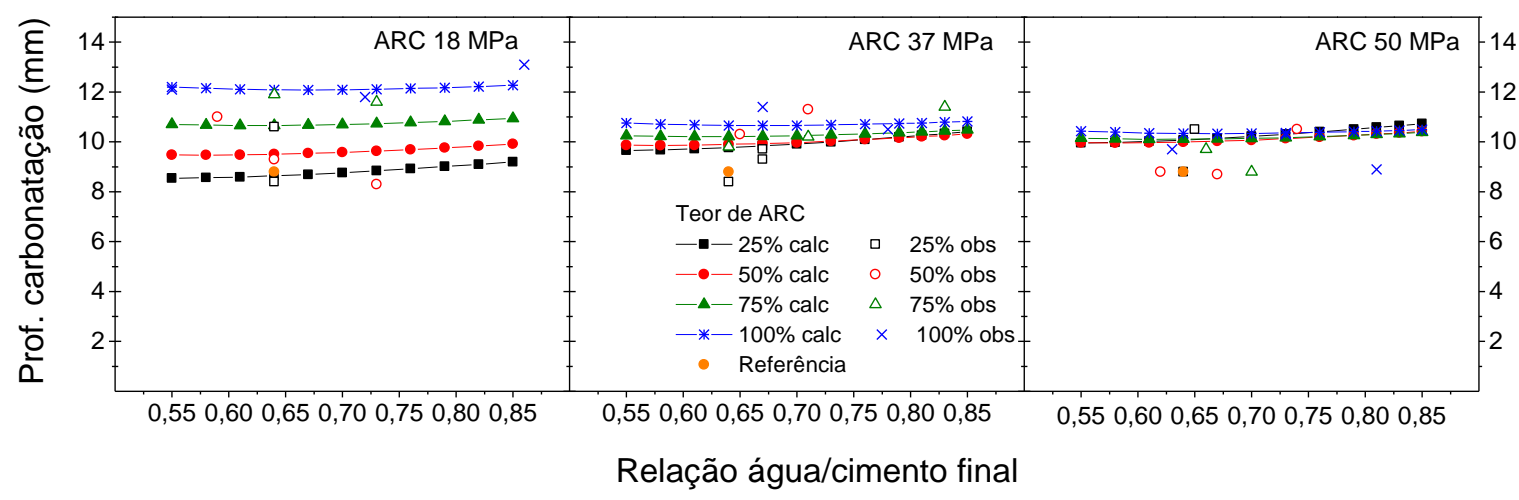

Figura 10 - Profundidade de carbonatação para concretos com ARC 18, 37 e 50 MPa aos 147 dias

Observando as curvas dos gráficos apresentados na Figura 10, fica evidente a mudança de comportamento quando da inserção de agregados mais porosos do que a nova matriz. Nota-se que agregados com porosidade menor $(50 \mathrm{MPa})$ ou similar $(37 \mathrm{MPa})$ à matriz $(32,5 \mathrm{MPa}, \mathrm{a} / \mathrm{c}=0,64)$ acarretam em uma profundidade de carbonatação que apresenta pequenas diferenças quando comparados os vários teores de agregados empregados. No entanto, quando foi empregado um agregado com maior porosidade (18 MPa) em relação à matriz, observa-se uma diferença mais expressiva na profundidade de carbonatação quando comparados os teores de agregado empregado e, em média, observa-se maior profundidade de carbonatação em relação aos concretos confeccionados com os demais tipos de agregados.

\section{Comentários finais}

Os ensaios realizados utilizando-se ARC provenientes de concretos com diferentes classes de resistência e elevado grau de hidratação (de modo a minimizar a possibilidade de o ARC possuir cimento anidro) demonstram que a porosidade do ARC utilizado é decisiva na carbonatação do novo concreto. A inserção de agregados cujo concreto de origem possui resistência igual ou superior à resistência do novo concreto tende a apresentar uma velocidade de carbonatação similar à do concreto de referência. No entanto, concretos com ARC cuja resistência do concreto de origem é inferior à resistência do concreto novo apresentam maior velocidade de carbonatação e maior dispersão de resultados.

\section{Referências bibliográficas}

ÂNGULO, S. C. Variabilidade de Agregados Graúdos de Resíduos de Construção Demolição reciclados. 155 f. 2000. São Paulo. Dissertação (Mestrado em Engenharia) - Escola Politécnica, Programa de Pós-graduação em Engenharia Civil, Universidade de São Paulo, São Paulo, 2000.

ÂNGULO, S. C. et al. Metodologia da Caracterização de Resíduos de Construção e Demolição. In: SEMINÁRIO DESENVOLVIMENTO SUSTENTÁVEL E A RECICLAGEM NA CONSTRUÇÃO CIVIL, 6., Sãod Paulo. Anais... São Paulo: IBRACON, 2003. 
ANDRADE, C. Manual para Diagnóstico de Obras Deterioradas por Corrosão de Armaduras. Tradução e adaptação de Antônio Carmona e Paulo Helene. Editora PINI, 1992.

ASSOCIAÇÃO BRASILEIRA DE NORMAS TÉCNICAS. NBR NM 101: concreto: ensaio de compressão de corpos-de-provacilíndricos. Rio de Janeiro, 1997.

ASSOCIAÇÃO BRASILEIRA DE NORMAS TÉCNICAS. NBR NM 8: determinação de resistência à tração por compressãodiametral. Rio de Janeiro, 1995.

ASSOCIAÇÃO BRASILEIRA DE NORMAS TÉCNICAS. NBR NM 248: agregados: determinação da composição granulométrica. Riode Janeiro, 2001.

ASSOCIAÇÃO BRASILEIRA DE NORMAS TÉCNICAS. NBR NM 52: agregado miúdo: determinação da massa específica e massa específica aparente. Rio de Janeiro,2009.

ASSOCIAÇÃO BRASILEIRA DE NORMAS TÉCNICAS. NBR NM 53: agregadograúdo: determinação de massa específica, massa específica aparente e absorçãode água. Rio de Janeiro, 2009.

ASSOCIAÇÃO BRASILEIRA DE NORMAS TÉCNICAS. NBR NM 45: agregados: determinação da massa unitária e do volume devazios. Rio de Janeiro, 2006.

BARY, B.; SELLIER, A. Coupled MoistureCarbon Dioxide-Calcium Transfer Model for Carbonation of Concrete. Cement and Concrete Research, v. 34, n. 10, p. 1859-1872, 2004.

BAUER, E.; NEPOMUCENO, A. A.; POZZAN, E. Caracterização da Estrutura de Poros em Microestruturas Carbonatadas e Sua Relação com Alguns Mecanismos de Transporte. In: WORKSHOP SOBRE DURABILIDADE DAS CONSTRUÇÕES, 2., 2001, São Paulo. Anais... São Paulo, 2001.

BAZUCO, R. S. Utilização de Agregados Reciclados de Concreto para a Produção de Novos Concretos. 1999. 103 f. Florianópolis. Dissertação (Mestrado em Engenharia) - PósGraduação em Engenharia Civil, Universidade Federal de Santa Catarina, Florianópolis, 1999.

BUTTLER, A. M. Concreto com Agregados Graúdos Reciclados de Concreto: influência da idade de reciclagem nas propriedades dos agregados e concretos reciclados. 2003. 187 f. São Paulo. Dissertação (Mestrado em Engenharia) Escola de Engenharia de São Carlos, Departamento de Engenharia de Estruturas, Universidade de São Paulo, São Paulo, 2003.
CABRAL, A. E. B. Modelagem de Propriedades Mecânicas e de Durabilidade de Concretos Produzidos com Agregados Reciclados, Considerando-se a Variabilidade da Composição do RCD. 248 f. 2007. São Paulo. Tese (Doutorado em Engenharia) - Escola de Engenharia de São Carlos, Universidade de São Paulo, São Paulo, 2007.

CABRAL, A. E. B. et al. Mechanical Properties Modeling of Recycled Aggregate Concrete.

Construction and Building Materials, v. 24, n. 4, p. 421-430, abr. 2010.

CASTELlOTE, M. et al. Chemical Changes and Phase Analysis of OPC Pastes Carbonated at Different $\mathrm{CO}_{2}$ Concentrations. Materials and Structures, v. 42, n. 4, p. 515-525, 2009.

CORDINALDESI, V.; MORICONI, G. Influence of Mineral Additions on the Performance of $100 \%$ Recycled Aggregate Concrete. Constructions and Building Materials, v. 23, n. 5, p. 2869-2876, maio 2009.

CSIRO. Guide for Specification of Recycled Concrete Aggregates (RCA) for Concrete Production: final report. Victoria: [s. n.], 1998. 19 p.

CUNHA, A. C. Q. da; HELENE, P. R.

Despassivação das Armaduras de Concreto por Ação da Carbonatação. São Paulo: Boletim Técnico da Escola Politécnica, 2001.

DIESEL, F. B. et al. Estudo da Carbonatação na Camada de Cobrimento do Concreto em Protótipos Com Altos Teores de Adição Mineral. In: ENCONTRO NACIONAL DE TECNOLOGIA DO AMBIENTE CONSTRUÍDO, 11., Florianópolis, 2006. Anais... Florianópolis: ENTAC, 2006.

ENVIRONMENTAL Protection Agency. Construction and Demolition Waste: waste management and resource use opportunities. Queensland: EPA, 2002.

ENVIRONMENTAL Protection Agency. EPA. Disponível em:<http://www.epa.gov/>. Acesso em: 14 jul. 2011.

ETXEBERRIA, M. et al. Influence of Amount of Recycled Coarse Aggregates and Production Process on Properties of Recycled Aggregate Concrete. Cement and Concrete Research, v. 37, n. 5, p. 735-742, maio 2007.

EUROPEAN COMMISSION. Report to DGXI: construction and demolition waste management practices, and their economic impacts. Belgica, 1999. 76 p. 
FIGUEIREDO, E. P. Mecanismo de Transporte de Fluidos no Concreto. In: ISAIA, G. C. Concreto, Ensino, Pesquisa e Realizações. São Paulo: IBRACON, 2005. v. 2.

GÓMEZ-SOBERÓN, J. M. V. Relationship Between gas Adsorption and the Shrinkage and Creep of Recycled Aggregate Concrete. Cement, Concrete and Aggregates, v. 25, n. 2, p. 42-48, 2003.

GOMES, M.; BRITO, J. de. Structural Concrete With Incorporation of Coarse Recycled Concrete and Ceramic Aggregates: durability performance. Materials and Structures, v. 42, n. 5, p. 663-675, jun. 2009.

HARTMANN, C. T. et al. Estudo da Influência da Relação Água/Cimento e da Consistência na Durabilidade dos Concretos Quanto à Penetração de Íons Cloreto e a Carbonatação. In: WORKSHOP SOBRE DURABILIDADE DAS CONSTRUÇÕES, 2., 2002, São José dos Campos, SP. Anais... São José dos Campos, SP, 2002.

HELENE, P. R. L. Contribuição ao Estudo da Corrosão em Armaduras de Concreto Armado. 231 f. 1993, São Paulo. Tese (Doutorado em Engenharia) - Escola Politécnica, Universidade de São Paulo, São Paulo, 1993.

HELENE, P.; TERZIAN, P. Manual de Dosagem e Controle do Concreto. São Paulo: Ed. Pini, 1993.

HUI-SHENG, S.; BI-WAN, X.; XIAO-CHEN, Z. Influence of Mineral Admixtures on Compressive Strength, Gas Permeability and Carbonation of High Performance Concrete. Construction and Building Materials, v. 23, p. 1980-1985, 2009.

KATZ, A. Properties of Concrete Made With Recycled Aggregate from Partially Hydrated Old Concrete. Cement and Concrete Research, New York, v. 33, n. 5, p. 703-711, 2003.

KAZMIERCZAK, C. S. Contribuição para a Análise da Eficiência de Películas Aplicadas Sobre Estruturas de Concreto Armado com o Objetivo de Proteção Contra a Carbonatação. 1995. 168f. São Paulo. Tese (Doutorado em Engenharia) - Escola Politécnica, Universidade de São Paulo, São Paulo, 1995.

KIRCHHEIM, A. P. Concreto de Cimento Portland Branco Estrutural: avaliação da carbonatação e absorção capilar. 168 f. 2003. São Paulo. Dissertação (Mestrado em Engenharia) Escola de Engenharia Civil, Universidade Federal do Rio Grande do Sul, Porto Alegre, 2003.
KULAKOWSKI, M. P. Contribuição ao Estudo da Carbonatação em Concretos e Argamassas Compostos com Adição de Sílica Ativa. 199 f. 2002. Porto Alegre. Tese (Doutorado em Engenharia) - Escola de Engenharia, Universidade Federal do Rio Grande do Sul, Porto Alegre, 2002.

LEITE, M. B. Avaliação de Propriedades Mecânicas de Concretos Produzidos com Agregados Reciclados de Resíduos de Construção e Demolição. 266 f. 2001. Porto Alegre. Tese (Doutorado em Engenharia) - Escola de Engenharia, Universidade Federal do Rio Grande do Sul, Porto Alegre, 2001.

LEVY, S. M. Contribuição ao Estudo da Durabilidade de Concretos, Produzidos com Resíduos de Concreto e Alvenaria. 182 f. 2001. São Paulo. Tese (Doutorado em Engenharia) Escola Politécnica, Universidade de São Paulo, São Paulo, 2001.

LIMBACHIYA, M. C.; LEELAWAT, T.; DHIR, R. K. Use of Recycled Concrete Aggregate in High-Stregth Concrete. Materials and Structures, v. 33, n., p. 574-580, nov. 2000.

LO, T. Y. et al. The Effect of High Temperature Curing on the Strength and Carbonation of Pozzolanic Structural Lightweight Concretes. Construction and Building Materials, v. 23, p. 1306-1310, 2009.

LOVATO, P. S. Verificação dos Parâmetros de Controle de Agregados Reciclados de Resíduos de Construção e Demolição para Utilização em Concreto. 180 f. 2007. Porto Alegre. Dissertação (Mestrado em Engenharia Civil) - Escola de Engenharia, Universidade Federal do Rio Grande do Sul, Porto Alegre, 2007.

MASCE, N. O.; MIYAZATO, S.; YODSUDJAI, W. Influence of Recycled Aggregate on Interfacial Transition Zone, Strength, Chloride Penetration and Carbonation of Concrete. Journal of Materials in Civil Engineering, v. 15, n. 5, p. 443-451, 2003.

MEIER, S. A. et al. Dynamics of the Internal Reaction Layer During Carbonation of Concrete. Chemical Engineering Science, v. 62, n. 4, p. 1125-1137, 2007.

MEIRA, G. R.; PADARATZ, I. J.; BORBA JÚNIOR, J. C. Carbonatação Natural de Concretos: resultados de cerca de quatro anos de monitoramento. In: ENCONTRO NACIONAL DE TECNOLOGIA DO AMBIENTE CONSTRUÍDO, 11., 2006, Florianópolis. Anais... Florianópolis: ENTAC, 2006. 
MELBOUCI, B. Compaction and Shearing Behavior of Recycled Aggregates. Construction and Building Materials, v. 23, n. 8, p. 2723-2730, 2009.

PADMINI, A. K.; RAMAMURTHY, K.; MATHEWS, M. S. Influence of Parent Concrete on the Properties of Recycled Aggregate Concrete. Construction and Building Materials, v. 23, n. 2, p. 829-836, 2009.

PAPADAKIS, V. G.; VAYENAS, C. G.; FARDIS, M. N. Fundamental Modeling and Experimental Investigation of Concrete Carbonation. ACI Materials Journal, v. 88, n. 4, p. 363-373, 1991.

PAULETTI, C. Análise Comparativa de Procedimentos para Ensaios Acelerados de Carbonatação. 176 f. 2004. Porto Alegre. Dissertação (Mestrado em Engenharia Civil) Escola de Engenharia, Universidade Federal do Rio Grande do Sul, Porto Alegre, 2004.

PAULETTI, C. Estimativa da Carbonatação Natural de Materiais Cimentícios a partir de Ensaios Acelerados e de Modelos de Predição. 238 f. 2009. Toulouse. Tese (Doutorado em Engenharia Civil) - Universidade Federal do Rio Grande do Sul e Institut National dês Sciences Appliquées de Toulouse, Toulouse, 2009.

PAULETTI, C. et al. Degradação do Concreto por Carbonatação: execução do ensaio. Revista Concreto, v. 53, p. 40-47, 2009.

PETER, M. A. et al. Competition of Several Carbonation Reactions in Concrete: a parametric study. Cement and Concrete Research, v. 38, n. 12, p. 1385-1393, 2008.

POON, C. S.; CHAN, D. Paving Blocks Made With Recycled Concrete Aggregate and Crushed Clay Bricks. Construction and Building Materials, v. 20, n. 5, p. 569-577, jun. 2006.

POSSAN, E. Contribuição ao Estudo da Carbonatação do Concreto Com Adição de Sílica Ativa em Ambiente Natural e Acelerado. 153 f. 2004. Porto Alegre. Dissertação (Mestrado em Engenharia Civil) - Escola de Engenharia, Universidade Federal do Rio Grande do Sul, Porto Alegre, 2004.

PUERTAS, F.; PALACIOS, M.; VÁZQUEZ, T. Carbonation Process of Alkali-Activated Slag Mortars. Journal of Materials Science, v. 41, n. 10, p. 3071-3081, 2006.
RYU, J. S. An Experimental Study on the Effect of Recycled Aggregate on Concrete Properties.

Magazine of Concrete Research, v. 54, n. 1, p. 7 12, 2002.

RILEM TC 116 PCD. Permeability of Concrete as a Criterion of Its Durability: concrete durability: an approach towards performance testing. Materials and Structures, v. 32, n. 217, p. 163-173, abr. 1999.

SONG, H. W.; KWON, S. J. Permeability Characteristics of Carbonated Concrete Considering Capillary Pore Structure. Cement and Concrete Research, v. 37, n. 6, p. 909-915, 2007.

TAM, V. W. Y.; GAO, X. F.; TAM, C. M. Microestructural Analysis of Recycled Aggregate Concrete Produced From Two-Stage Mixing Approach. Cement and Concrete Research, v. 35, p. 1195-1203, 2005.

THIERY, M. et al. Investigation of the Carbonation Front Shape on Cementitious Meterials: effects of the chemical kinetics. Cement and Concrete Research, v. 37, p. 10471058, 2007.

VENQUIARUTTO, S. D.; ISAÍA, G. C.; GASTALDINI, A. L. G. Carbonatação do Concreto Estrutural Com Altos Teores de Adições Minerais e Diferentes Finuras. In: ENCONTRO NACIONAL DO AMBIENTE CONSTRUÍDO, 9. 2002, Foz do Iguaçu. Anais... Foz do Iguaçu: ENTAC, 2002.

XIAO, J.; LI, J.; ZHANG, C. Mechanical Properties of Recycled Aggregate Concrete Under Uniaxial Loading. Cement and Concrete Research, v. 35, p. 1187-1194, 2005.

WANG, X. Y.; LEE, H. S. A Model for Predicting the Carbonation Depth of Concrete Containing Low-Calcium Fly Ash. Construction and Building Materials, v. 23, p. 725-733, 2009.

WERLE, A. P. Determinação de Propriedades de Concretos Com Agregados Reciclados de Concreto, Com Ênfase na Carbonatação. 159 f. 2010 São Leopoldo. Dissertação (Mestrado em Engenharia Civil) - Universidade do Vale do Rio dos Sinos, São Leopoldo, 2010.

\section{Agradecimentos}

Os autores agradecem à CAPES, FINEP e PLANO

DE BACIA SINOS pelo apoio à pesquisa. 


\section{Revista Ambiente Construído}

Associação Nacional de Tecnologia do Ambiente Construído Av. Osvaldo Aranha, $99-3^{\circ}$ andar, Centro

Porto Alegre - RS - Brasil

CEP $90035-190$

Telefone: +55 (51) 3308-4084

Fax: +55 (51) 3308-4054

www.seer.ufrgs.br/ambienteconstruido

E-mail: ambienteconstruido@ufrgs.br

228 Werle, A. P.; Kazmierczak, C. de S.; Kulakowski, M. P. 